\title{
Determination of the safety factor of the slope in homogenous low-height earth dams using pseudo-static stability analysis
}

\author{
Meisam Imandash ${ }^{1}$, Seyed Mohammad Mirmoa'zen ${ }^{2}$, Mohammad Nikookar ${ }^{2, *}$ \\ ${ }^{1}$ Department of Civil Engineering, University of Semnan, Semnan, Iran \\ ${ }^{2}$ Department of Civil Engineering, University of Guilan, Rasht, Iran
}

\section{A R T I C L E I N F O}

\section{Article history:}

Received 21 July 2017

Received in revised form

22 September 2017

Accepted 1 October 2017

\section{Keywords:}

Earth dam

Slope

Safety factor

Stability

\begin{abstract}
A B S T R A C T
The Stability of earth structures is among the most important problems in geotechnical engineering. Since earthquakes are very important reasons for the instability of these structures, the dynamic analysis of earth structures is of high importance. Homogenous low-height earth dams are one of the most widely used types of earth structures. These dams, which are usually waterproofed with geomembranes, are very suitable for storing water and other liquids. Due to having low costs and not being difficult to construct, they don't need complicated engineering calculations and to ensure their safety, only knowing the slopes of the embankments will suffice. In this study, a set of graphs is provided, which makes it possible to quickly calculate the safety factor of the slopes in earth dams up to $10 \mathrm{~m}$ high under static and pseudo-static conditions. In this paper, a numerical comparison between different methods for the analysis of the stability potentials of the slopes during earthquakes is also presented.
\end{abstract}

(C) 2017 The Authors. Published by IASE. This is an open access article under the CC BY-NC-ND license (http://creativecommons.org/licenses/by-nc-nd/4.0/).

Mendoza et al. (2009), in a study, conducted a pseudo-static analysis of low-height earth dams using the normal limit equilibrium method. Currently, there is a need for a more accurate and up-to-date analysis since more accurate and practical methods such as the finite difference method exists. In this study, in addition to that, a stability analysis of these slopes using other limit equilibrium methods and also finite difference method is done and the results obtained are compared.

\section{Related works}

In the past years, numerous studies on the seismic response of different dams around the world have been conducted. Among these studies we can refer to M. Ozkan (1998) studied seismic safety considerations of embankments, earth dams and masonry dams. Also in 2001, Rathje and Bray (2001) conducted one- and two-dimensional seismic analyses of embankments. In 2008, Karbor-eshyadeh and Soroush (2008) conducted a numerical analysis of inclined and vertical gravity dams with clay cores and compared their behavior. Yegian et al. (1991) analyzed seismic deformation of earth dams. Parish et al. (2009) analyzed the seismic response of an earth dam using the finite element method and compared the results obtained during centrifuge tests. Wieland (2008) studied the safety of small dams against earthquakes. In this study, while 
referring to the fact that numerous rural dams in many countries such as India are made by companies with no expertise in dam engineering and without the consideration of a safety factor, he insists that these dams must be upgraded or decommissioned. Parish et al. (2009) conducted a numerical analysis of the seismic response of earth dams' cores and crusts using the simple and famous Mohr-Coulomb failure criterion method. The results obtained from the analysis of models subjected to records of real earthquakes suggest the plastification of large portions of the crust and a minor portion of the core. In fact, these analyses suggest that the mentioned plastification has a significant effect on the seismic response of dams as it leads to energy loss and the reduction of the natural frequency. As a result, plastic analysis is an appropriate tool for the analysis of the seismic response of earth dams. Mendoza et al. (2009), in a comprehensive study on homogeneous earth dams fewer than $10 \mathrm{~m}$ high, offered a set of graphs for speeding the calculation of safety factors. The safety factors obtained from these graphs are more conservative than the ones calculated with other common methods. Tripathy (2011) conducted a seismic analysis of earth dams. In fact, this research shows that the mentioned failure occurs even during small earthquakes and concludes that choosing the appropriate earth type and compaction factors is an important part of the design and construction of earth dams.

Subramani et al. (2012) in a study, with the aim of providing a set of standards for the design of concrete gravity dams, conducted seismic and stability analyses of these dams using the Staad PRO software. This software, based on the weight method, equilibrium of rigid bodies, and the beams theory, is used for stress analysis and the calculation of crack length and safety factor. The results of the study conducted suggested that the Staad PRO software had great flexibility in modeling the assumptions and calculation methods and that these assumptions, which are related to loading conditions, cracking criteria, uplift pressure, and analysis methods, could be used in static, seismic, and post-seismic analyses.

In another study, Samir and Sanghavi (2012) carried out a dynamic analysis of Kaswati earth dam considering the fact that liquefaction occurs in upstream and downstream slopes as well as the foundation of the dam due to the existence of cohesion-less soil in the foundation. The methods employed in the analysis of the liquefaction potential were the common methods of Cyclic Stress Ratio (CSR) and Cyclic Resistance Ratio (CRR), used for the measurement of the earthquake load and soil resistance respectively. The factor of safety was obtained as the ratio of the cyclic stress ratio to the critical stress ratio. Lastly, in order to prevent liquefaction, replacement of the liquefaction-prone soil in the foundation with a type of well-graded soil and a factor of safety greater than 1 was suggested.

Iman et al. (2012) conducted a dynamic analysis of concrete gravity dams under great earthquake loads using the ANSYS 12 software. The model used in this study was the Dezful gravity dam, categorized as a low-height dam with a spillway about $10 \mathrm{~m}$ high. Based on the results obtained, the maximum movement of $0.24 \mathrm{~cm}$ was observed in the tower during Manjil and Anza earthquake. The tensile stress in the pivot of the dam caused by Manjil and Anza earthquake was more than the approved stress and could cause cracks in the body of the dam.

\section{Methodology}

Low-height dams, due to the simplicity and low costs of their construction, do not need complicated engineering calculations, and to ensure their geotechnical safety, only knowing the stable embankment slopes suffices. Thus in this paper, along with the presentation of the resulted graphs, we first study the method for the fast calculation of the safety factor of slope in earth dams up to $10 \mathrm{~m}$ high under static and pseudo-static conditions and then with a numerical comparison between different methods, the stability potential analysis of the slopes during earthquakes is conducted.

This study, with the presentation of a series of graphs, provides the means of instantly calculating the safety factor of the slope in earth dams up to $10 \mathrm{~m}$ high under static and pseudo-static conditions. In this paper, a numerical comparison between the different methods for the stability potential analysis of the slopes during earthquakes is also made.

Different rules and regulations exist for the stability of the slopes in earth dams. For instance, Bureau of Reclamation suggests a minimum safety factor value of about 1.5 for the stability of dams while USDA establishes safety factor values of 1.1 (for slopes with full reservoir and earthquake conditions) and 1.5 (for slopes with full reservoir and without earthquake conditions). According to the aforementioned values, a safety factor value of 1.4 , which is approximately the average of the values, could be appropriate for the stability of slopes.

Several parameters affect the calculation of the safety factor of the slope in a small earth dam. In this paper, the safety factor for the stability of the slope, with the assumption of a wide range for the parameters affecting it, is calculated. The most effective of these parameters, the ranges assumed for them in this study, and the reason for their effectiveness is also introduced.

\subsection{Height of the dam}

In this research, in order to study the effect of the height of the dam on its stability, three different dam height categories were examined: dams less than $2.5 \mathrm{~m}$ high, dams between 2.5 and $5 \mathrm{~m}$ high, and dams between 5 and $7.5 \mathrm{~m}$ high. The reason for this choice is that the dimensions of the most of the dams used for agricultural and urban leachate storage fall into these three height categories. 


\subsection{Slopes of the dam}

Slopes of an earth dam could be from a wide range depending on the type and strength of the materials used. In this research, in order to study the effect of the slope, for each height of the embankment, three different slopes of $45^{\circ}(1 \mathrm{~V}: 1 \mathrm{H})$, $26.65^{\circ}(1 \mathrm{~V}: 2 \mathrm{H})$, and $18.43^{\circ}(1 \mathrm{~V}: 3 \mathrm{H})$ were analyzed.

\subsection{Mechanical properties of the material}

The most important material parameters which affect the stability of earth dams are the density, effective cohesion, and effective friction angle.

1. The density of the material has less variation in comparison to the other parameters. Thus, according to USBR (2001), an average value of 2 (ton $/ \mathrm{m} 3$ ) is chosen for this parameter.

2. The effective friction angle varies greatly for different types of soil depending on the particle size and aggregate type. In this study, the angles of $\varphi^{\prime}=10^{\circ}, \varphi^{\prime}=20^{\circ}, \varphi^{\prime}=30^{\circ}$, and $\varphi^{\prime}=40^{\circ}$ are taken as effective friction angles.

3. The effective cohesion $\left(c^{\prime}\right)$ also varies greatly for different types of soil depending on the clay percentage, the material's Atterberg limits, and the over consolidation ratio.

\subsection{Seismic coefficient}

Iran, with the existence of numerous active and inactive faults, is considered an unsafe country in terms of seismicity and seismotectonic hazards. Thus, the analysis of the effect of dynamic earthquake loads on the slopes of earth dams is of high importance. In this research, three different values of $\mathrm{SC}=0, \mathrm{SC}=0.1$, and $\mathrm{SC}=0.2$ were taken as pseudo-static seismic coefficients.

\section{Modelling}

Numerical modelling and the three software programs of GeoSlope, Geostudio, and FLAC are used for the limit equilibrium and stress-strain analyses of dams. The software used for the limit equilibrium analysis must be capable of modelling different soil behaviors using the appropriate behavior laws and different safety factor calculation methods. The software used for the stress-strain analysis must be capable of modelling the plastic behavior of the soil using the appropriate behavior laws along with the modelling of large deformations, pore water pressure, and tensile cracks.

\subsection{SLOPE/W program of the GeoSlope software pack}

For the calculation of the safety factor against sliding using the method of slices, also known as the limit equilibrium method, the SLOPE/W program of the Canadian GeoSlope software (SLOPE/W, 2007) pack was used. This program is capable of calculating the stability of the slopes under different static and pseudo-static (earthquake) loading conditions. It analyzes the stability problems in a two-dimensional mode and calculates the safety factor for circular and non-circular surfaces using different methods. Other capabilities of this program include the consideration of the additional pore water pressure due to the construction stage loading, earthquake loading and the water pressure related to different piezometric surfaces. In addition, pseudo-static stability analysis of the slope could be conducted by defining horizontal and vertical seismic coefficients for the loading condition.

\subsection{Geostudio 2007 software pack}

Geostudio 2007 software pack is used for the stability analysis of sloped surfaces and the determination of the safety factor (FOS) in slope design. The mentioned calculations are by default done using the limit equilibrium methods such as Janbu (1967), Ordinary, and Bishop and Morgenstern (1960).

Along with the limit equilibrium methods, the computer program could also use other methods including GLE, Spencer (1967), and Morgenstern (1963). In this study, the Morgenstern method was also employed for stability analysis. It should be noted that the minimum safety factor which ensures the stability of a slope must be equal to unity, but in design procedures, this minimum value is normally considered equal to 1.5. It should also be noted that the computer program of Geostudio software pack available for stability analysis, unlike the other programs included in the pack, does not employ the finite element method. It uses a collection of graphical methods instead. The most important features of this program include the option for modelling common types of reinforces such as bearings, soil nailings, and geofabrics used for increasing the safety of slopes.

\subsection{FLAC software program}

The FLAC (2002) software program is developed based on the finite difference method. The word FLAC is the abbreviation of 'Fast Lagrangian Analysis of Continua'. This program is used in continuous environments, especially soil and rock, which fail by yielding in a plastic manner. Thus it can be used in geotechnical engineering applications. It is also capable of solving complicated geotechnical problems.

The FLAC SLOPE program is one section of the FLAC software which can be used for the fast calculation of the safety factor. This program operates based on the limit equilibrium methods and calculates the safety factor using the Ordinary Method of Slices. In this paper, this program was also employed. 


\section{Results and discussion}

The examples chosen for the calculation of the safety factor of slope were modelled using the aforementioned programs. In the following, the results obtained are analyzed along with the presentation of the related graphs and tables.

The models created are based on the general form of the earth dams presented in Figs. 1-3.

The models created using the FLAC and Slope/W software programs are presented in Figs. 4-6 and Figs. 7-9 respectively.

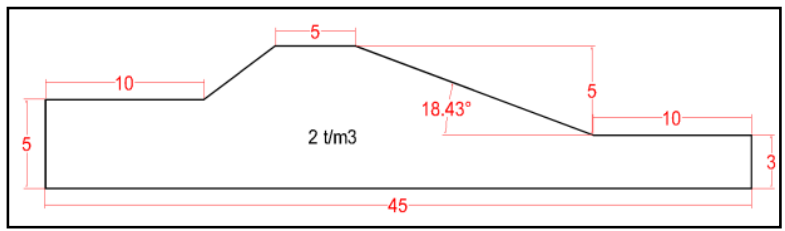

Fig. 1: Model created for the height of $5 \mathrm{~m}$ and the slope of $18.43^{\circ}$

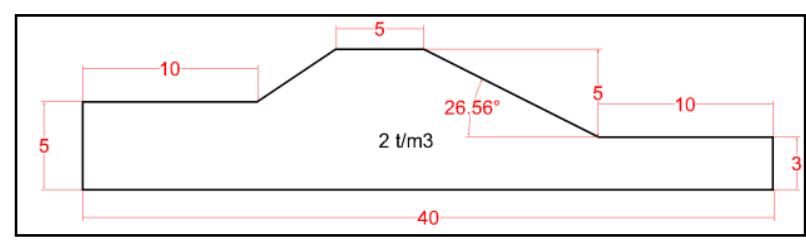

Fig. 2: Model created for the height of $5 \mathrm{~m}$ and the slope of $26.56^{\circ}$

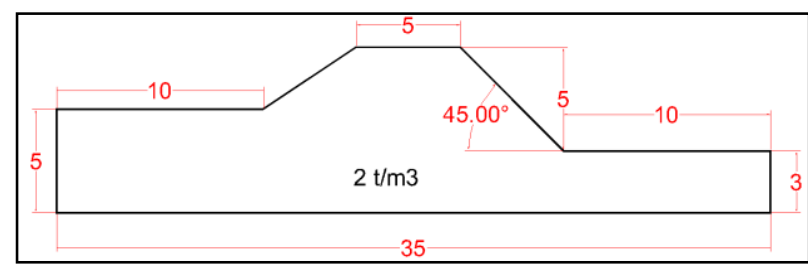

Fig. 3: Model created for the height of $5 \mathrm{~m}$ and the slope of $45^{\circ}$

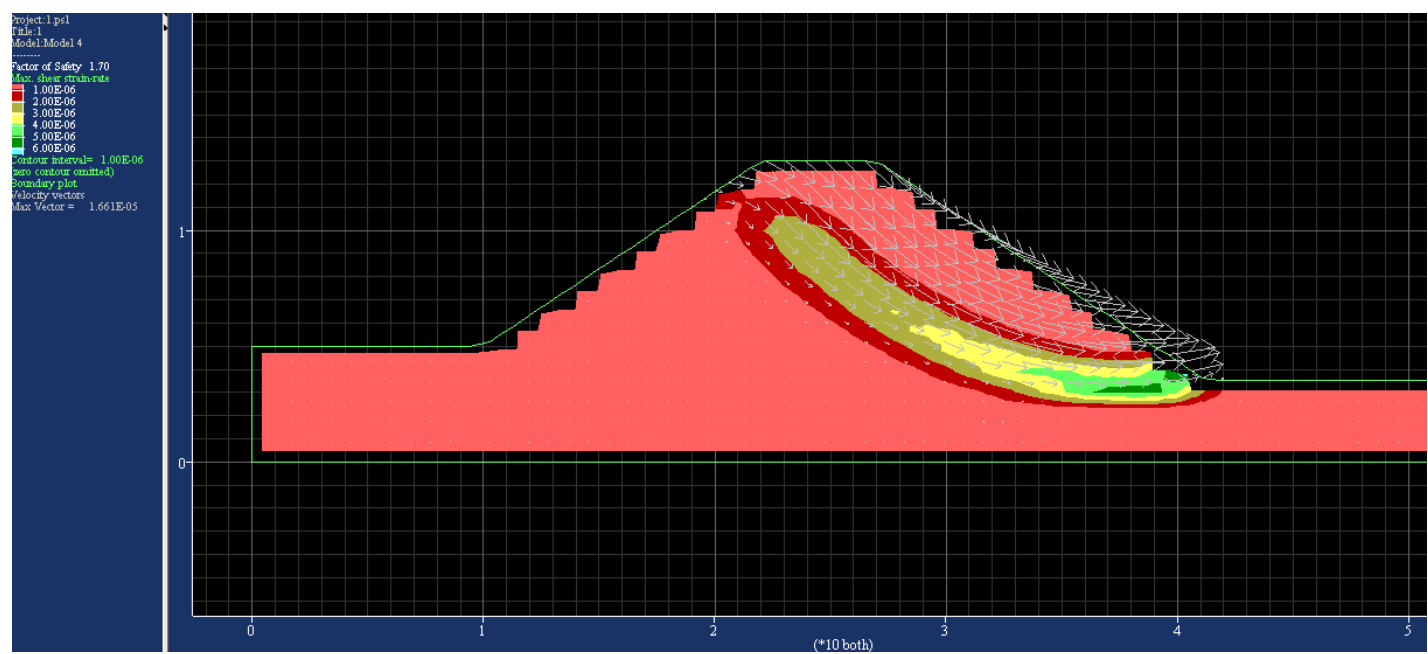

Fig. 4: Model created for the height of $7.5 \mathrm{~m}$ and the slope of $45^{\circ}$
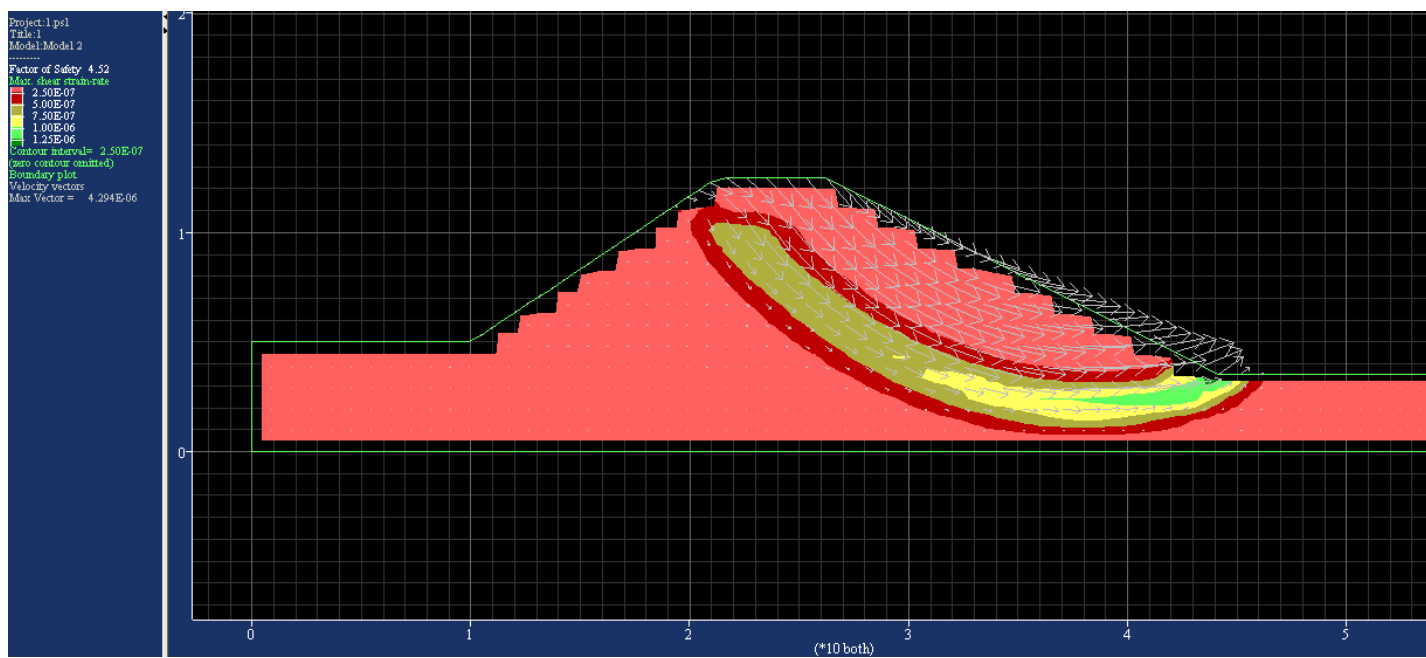

Fig. 5: Model created for the height of $7.5 \mathrm{~m}$ and the slope of $26.56^{\circ}$

\subsection{Verification of the accuracy of the calculations}

In order to verify the accuracy of the static calculations, a numerical comparison between the safety factors obtained for different small earth dams using different methods of analysis for static conditions was conducted. In Table 1, the specifications for homogeneous earth dams with a height of $5-7.5 \mathrm{~m}$ are presented. Other researcher's study results are presented in Table 2 . The results in this study, obtained using the GeoSlope software 
program and different methods, are presented in Table 3. The analysis and comparison of the aforementioned results, as presented in Table 4, show that the values obtained are very close.
Nomograms for the fast calculation of the safety factor obtained using the SLOPE/W program are presented in Figs. 10-12. Nomograms obtained using the FLAC SLOPE program is also presented in Figs. 13 and 14.

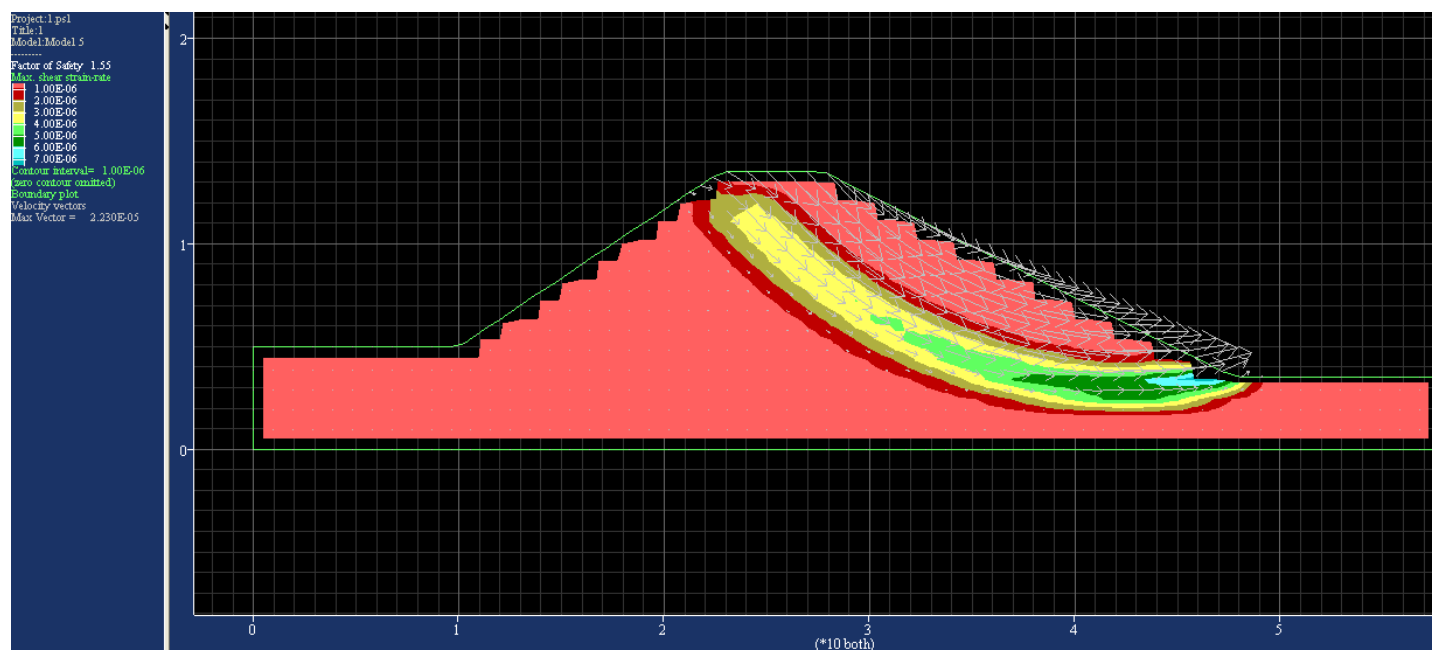

Fig. 6: Model created for the height of $7.5 \mathrm{~m}$ and the slope of $18.43^{\circ}$

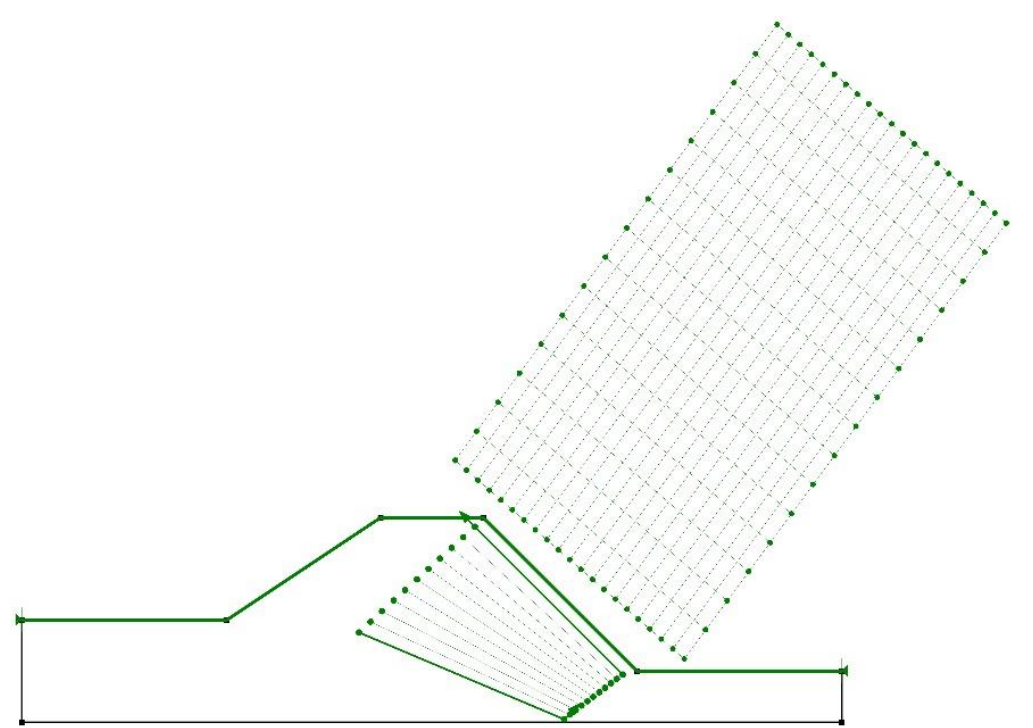

Fig. 7: Model created for the height of $7.5 \mathrm{~m}$ and the slope of $45^{\circ}$

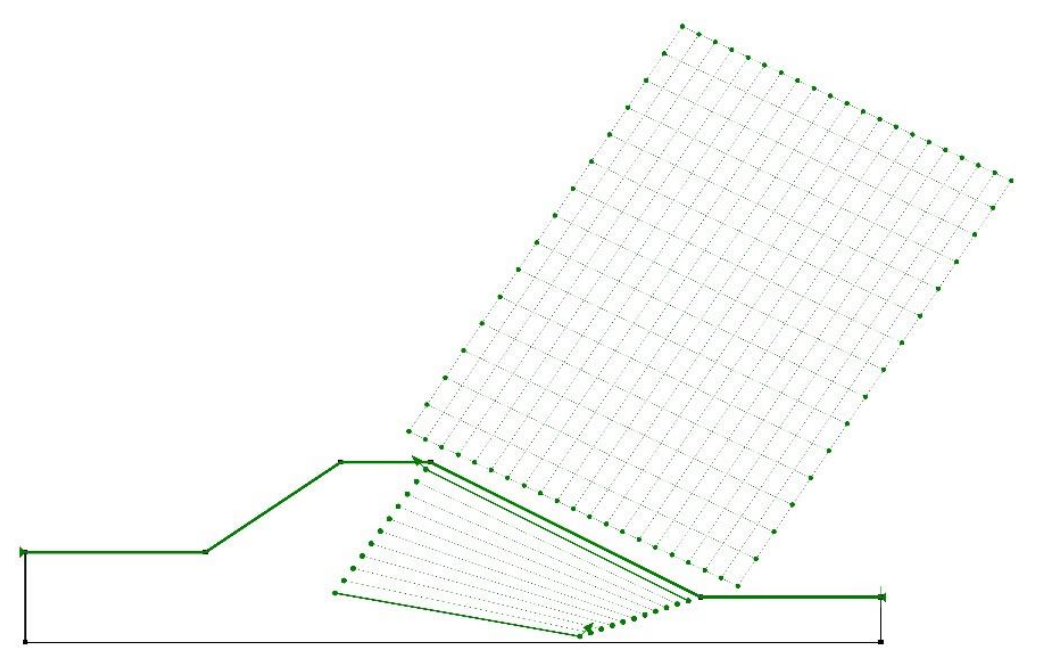

Fig. 8: Model created for the height of $7.5 \mathrm{~m}$ and the slope of $26.56^{\circ}$ 


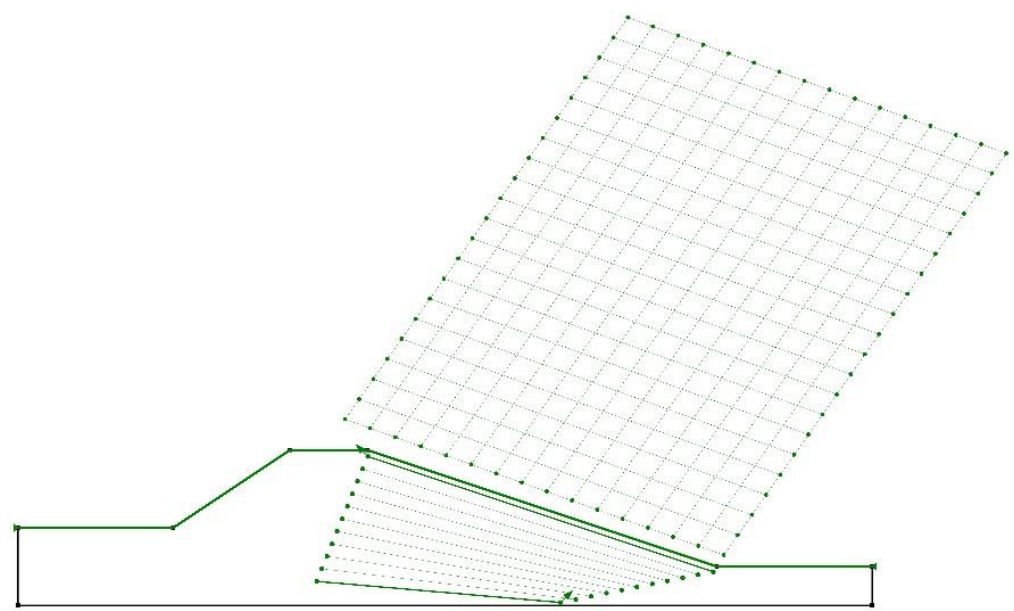

Fig. 9: Model created for the height of $7.5 \mathrm{~m}$ and the slope of $18.43^{\circ}$

Table 1: Geotechnical specifications of six different earth dams (Mendoza et al., 2009)

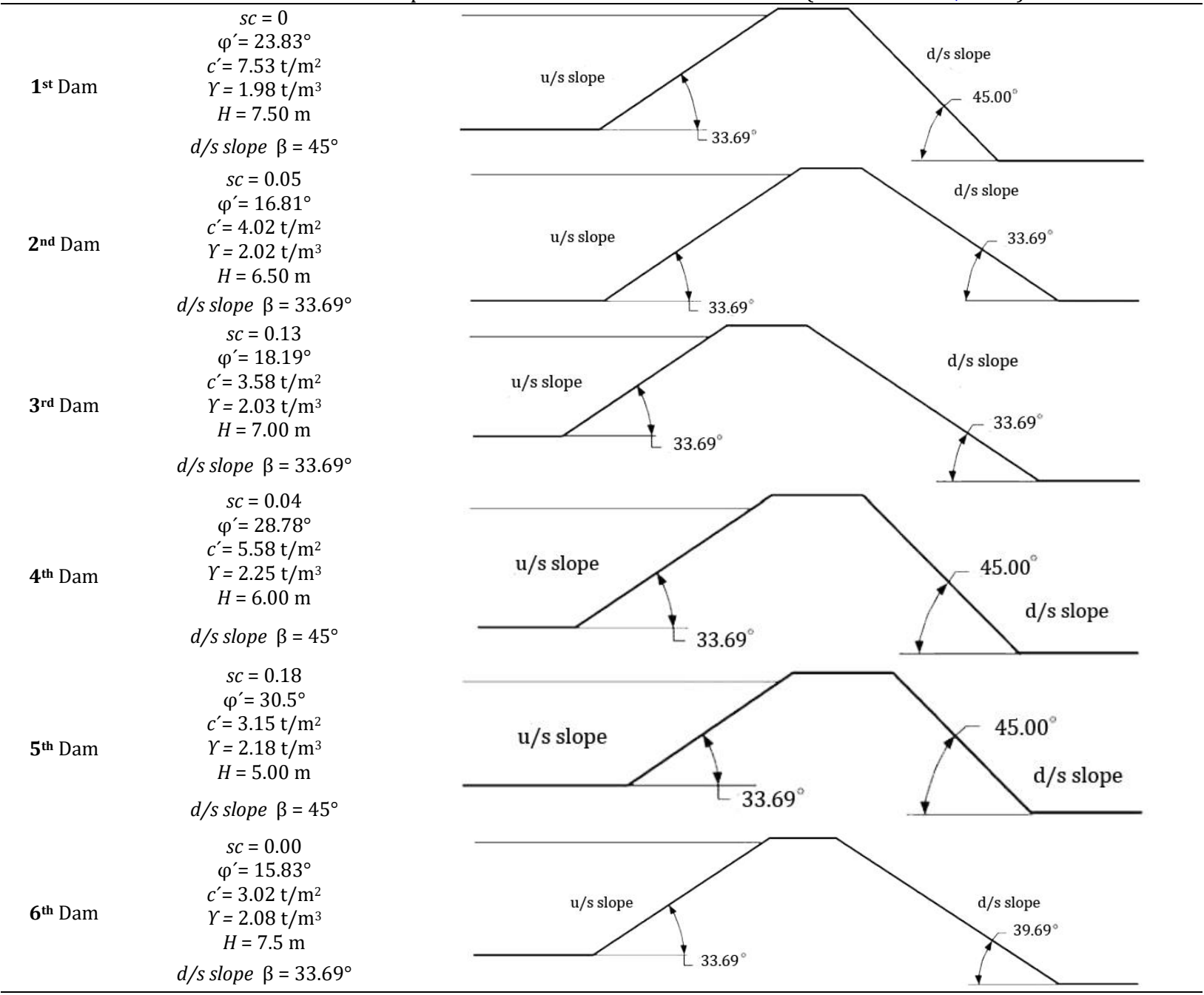

Table 2: Results obtained by other researchers (Mendoza et al., 2009)

\begin{tabular}{lcccc}
\hline & Slices & Bishop and Morgenstern & Jambu simpl. & Jambo correc. \\
\cline { 2 - 5 } 1st dam & 3.87 & 3.96 & 3.87 & 4.18 \\
2nd dam & 2.45 & 2.55 & 2.37 & 2.56 \\
3rd dam & 2 & 2.08 & 1.87 & 1.99 \\
4th dam & 3.39 & 3.46 & 3.29 & 3.47 \\
5th dam & 2.39 & 3.42 & 2.31 & - \\
6th dam & 2.08 & 2.13 & 2.05 & - \\
\hline
\end{tabular}


Table 3: Safety factor analysis results obtained using the nomograms presented in this research

\begin{tabular}{|c|c|c|c|c|c|c|c|c|c|c|c|}
\hline 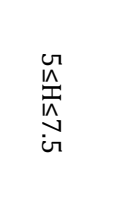 & 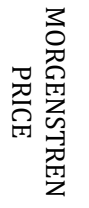 & 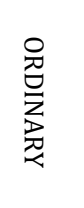 & 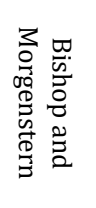 & 胥 & 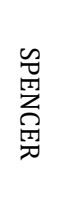 & $\stackrel{2}{P}$ & $\begin{array}{l}\text { Оి } \\
\text { ర } \\
⺊\end{array}$ & $\begin{array}{l}\text { О } \\
\text { స̃ } \\
\text { N }\end{array}$ & 蛋 & 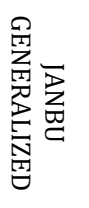 & 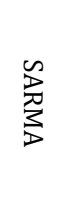 \\
\hline 1st dam & 3.938 & 3.888 & 3.96 & 3.89 & 3.94 & 3.91 & 4.064 & 4.19 & 4.113 & 4.061 & 3.937 \\
\hline 2nd dam & 2.557 & 2.482 & 2.56 & 2.404 & 2.559 & 2.557 & 2.587 & 2.675 & 2.486 & 2.576 & 2.552 \\
\hline 3rd dam & 1.973 & 1.923 & 1.976 & 1.84 & 1.975 & 1.974 & 1.936 & 1.989 & 1.939 & 1.999 & 1.971 \\
\hline 4th dam & 3.43 & 3.397 & 3.432 & 3.364 & 3.432 & 3.43 & 3.471 & 3.568 & 3.467 & 3.443 & 3.427 \\
\hline 5th dam & 2.256 & 2.193 & 2.258 & 2.098 & 2.313 & 2.256 & 2.188 & 2.27 & 2.183 & 2.214 & 2.255 \\
\hline 6th dam & 2.012 & 1.953 & 2.015 & 1.916 & 2.013 & 2.012 & 2.096 & 2.144 & 2.091 & 1.972 & 2.009 \\
\hline
\end{tabular}

Table 4: Comparison of the obtained results

$\begin{array}{lcr} & \text { Reference- Bishop and Morgenstern } & \text { User- Bishop and } \\ \text { 1st dam } & 3.9 & 3.9 \\ \text { 2nd dam } & 2.5 & 2.5 \\ \text { 3rd dam } & 2 & 1.9 \\ \text { 4th dam } & 3.4 & 3.4 \\ \text { 5th dam } & 2.4 & 2.2 \\ \text { 6th dam } & 2.1 & 2\end{array}$

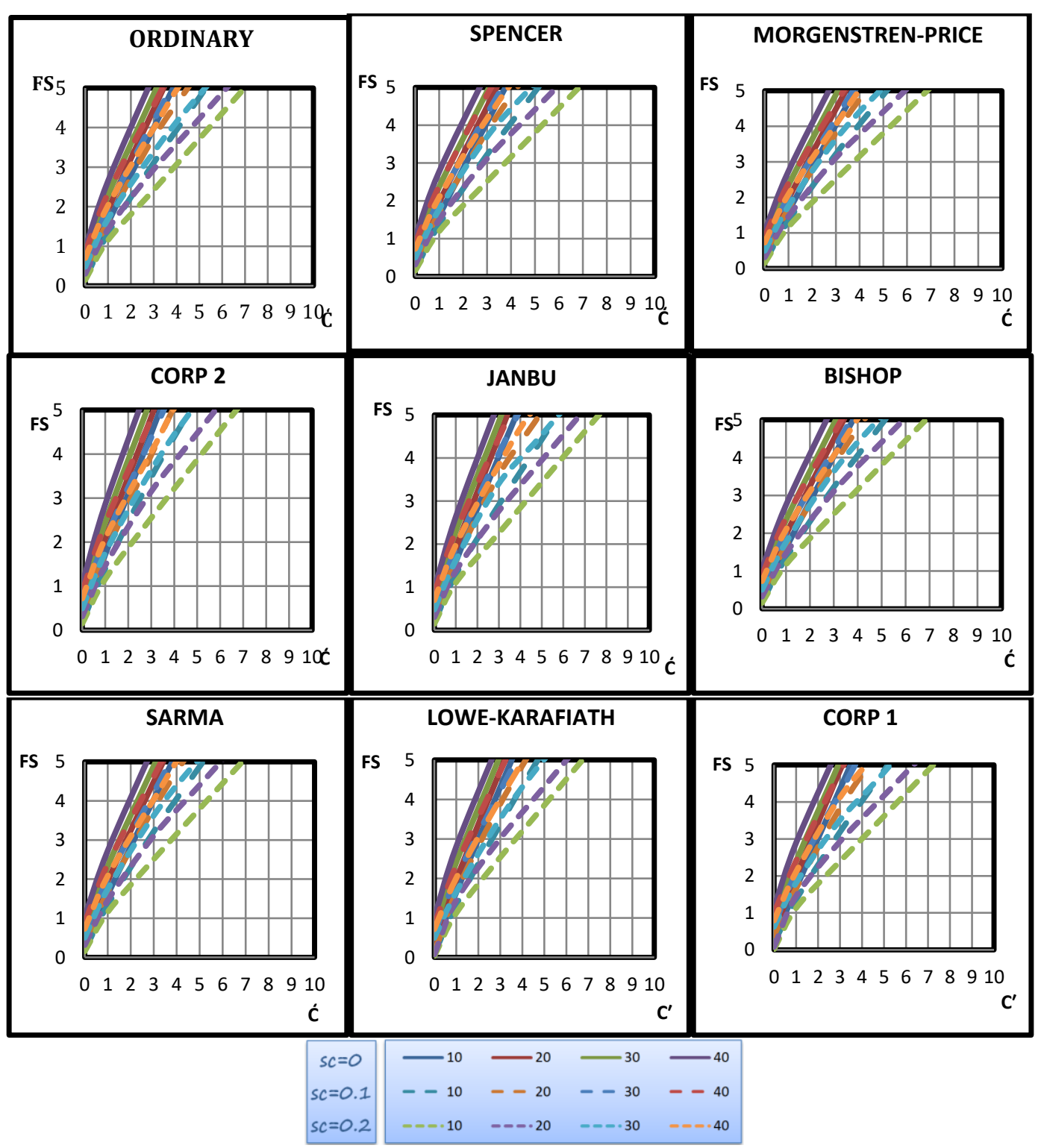

Fig. 10: Nomograms for the calculation of the safety factor of earth dams with the height of $2.5 \mathrm{~m}$ and the slope of $45^{\circ}$ using different analysis methods 


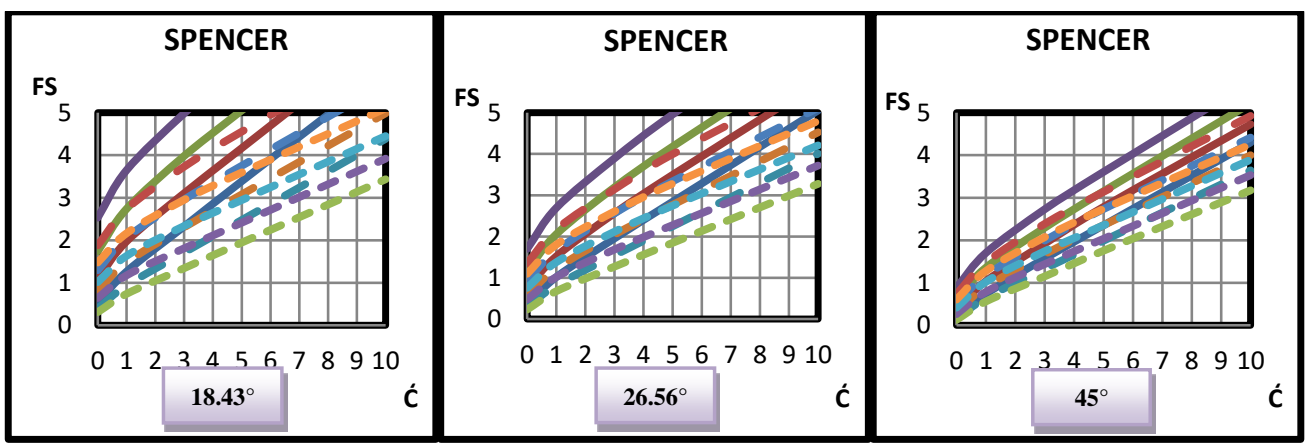

Fig. 11: Increase of the safety factor due to the decrease of the slope in earth dams with the height of $7.5 \mathrm{~m}$

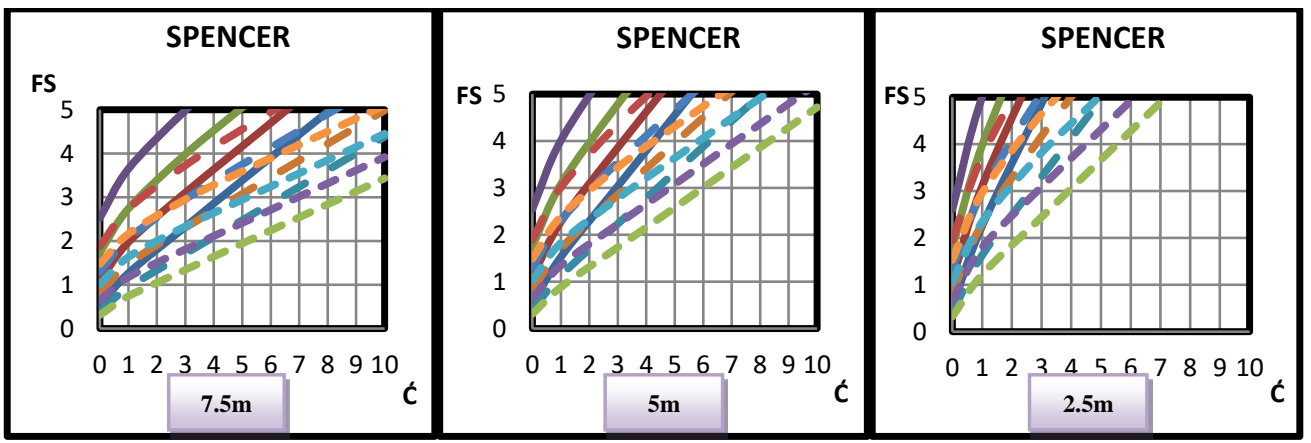

Fig. 12: Decrease of the safety factor due to the increase of the height in earth dams with the slope of 18.43

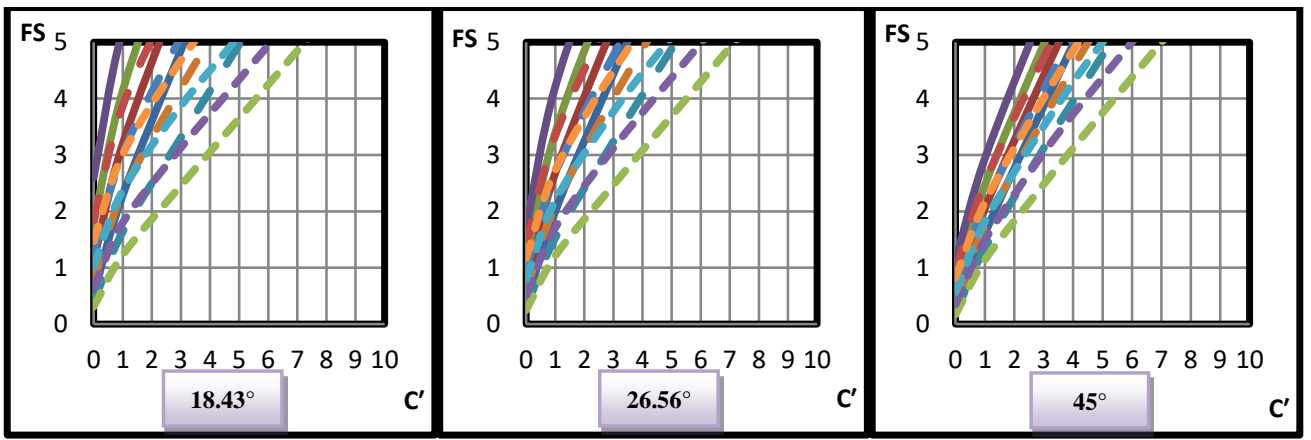

Fig. 13: Increase of the safety factor due to the decrease of the slope in earth dams with the height of $2.5 \mathrm{~m}$

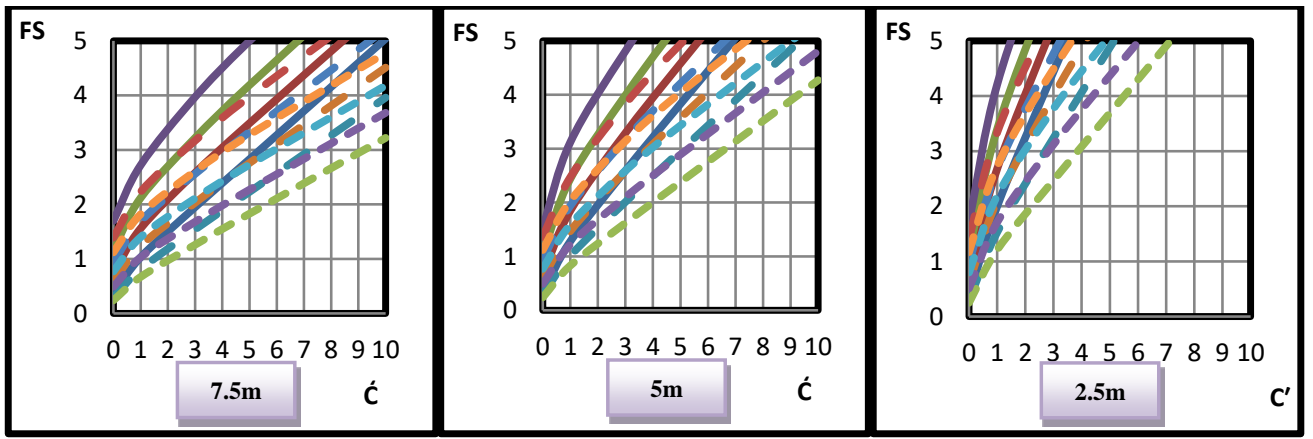

Fig. 14: Decrease of the safety factor due to the increase of the height in earth dams with the slope of $26.56^{\circ}$

Through the comparison of the nomograms, it can be clearly observed that in embankments with the same height, the safety factor increases as the slope decreases. Meanwhile, the safety factor drastically decreases as the height of embankments increases. The increase of the seismic coefficient also leads to the decrease of the safety factor.

In limit equilibrium analysis methods, the difference between the employed methods becomes increasingly apparent with the increase of the friction angle and cohesion. As can be seen, among the different methods, the Spencer method is more accurate than the others as this method simultaneously satisfies the equilibriums of both moments and forces.

It should be noted that the results obtained using both programs are very close, thus signifying the accuracy of the calculations.

In Table 5, the results obtained for the stability safety factor, calculated using the finite difference method and the presented nomograms, are shown for given soil specifications and different dimensions and slope geometries. The specifications of the soil 
studied include the effective cohesion of $3 \mathrm{KN} / \mathrm{m} 2$ and the fiction angle of $10^{\circ}$.

As seen in the fallowing results, the increase of the height or the slope and also the increase of the seismic coefficient, lead to the decrease of the safety factor of the slope (Figs. 15-20).

Table 5: Results of the calculations using the finite difference method

\begin{tabular}{|c|c|c|c|c|c|c|c|c|c|c|}
\hline \multicolumn{2}{|c|}{ SC } & \multicolumn{3}{|c|}{0} & \multicolumn{3}{|c|}{0.1} & \multicolumn{3}{|c|}{0.2} \\
\hline & & 18.43 & 25.65 & 45 & 18.43 & 25.65 & 45 & 18.43 & 25.65 & 45 \\
\hline $\begin{array}{c}C=3 \\
\varphi=10\end{array}$ & $\mathrm{H}=2.5$ & 3.1 & 2.5 & 2.1 & 2.3 & 2.1 & 1.9 & 1.9 & 1.8 & 1.7 \\
\hline $\begin{array}{c}C=3 \\
\varphi=10\end{array}$ & $\mathrm{H}=5$ & 3 & 2.4 & 2 & 2.2 & 2 & 1.8 & 1.8 & 1.7 & 1.5 \\
\hline $\begin{array}{c}C=3 \\
\varphi=10\end{array}$ & $H=7.5$ & 2.2 & 1.9 & 1.5 & 1.5 & 1.4 & 1.3 & 1.3 & 1.2 & 1.1 \\
\hline
\end{tabular}

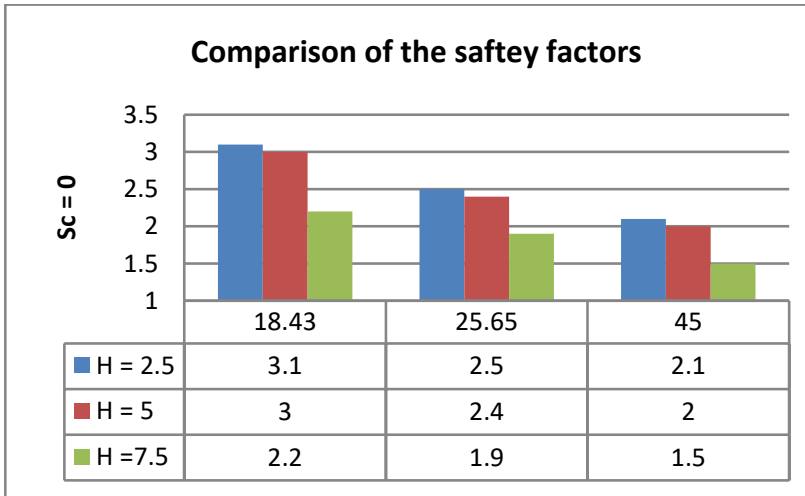

Fig. 15: Comparison of the safety factors of the slope with the seismic coefficient of 0

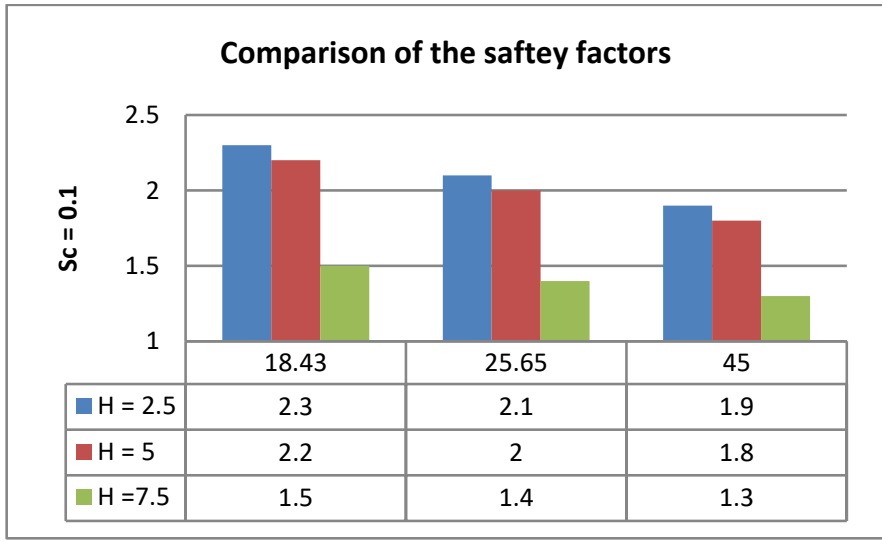

Fig. 16: Comparison of the safety factors of the slope with the seismic coefficient of 0.1

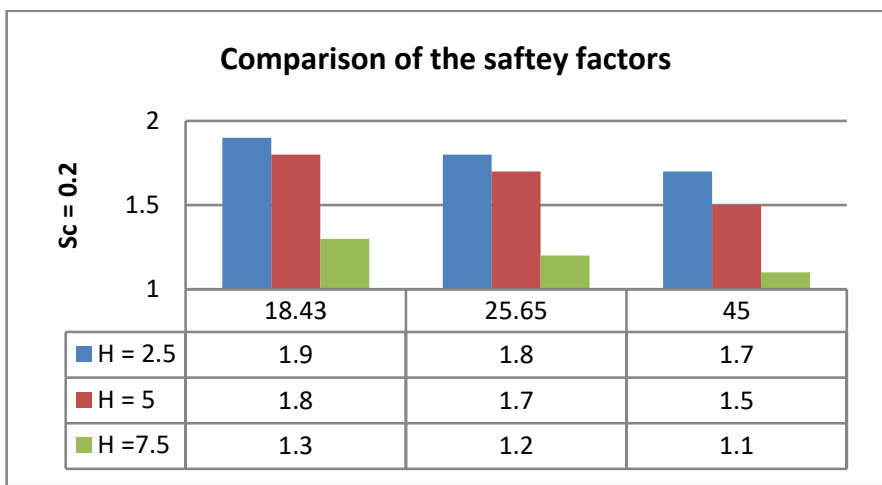

Fig. 17: Comparison of the safety factors of the slope with the seismic coefficient of 0.2 


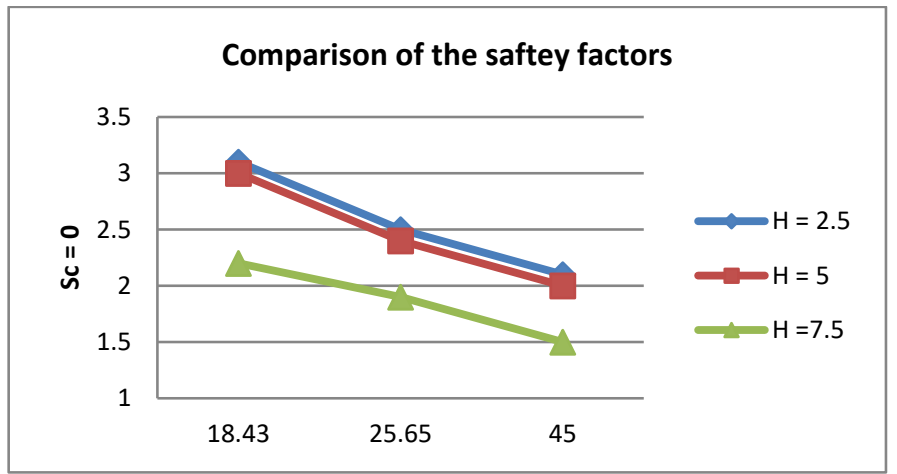

Fig. 18: Graphs of safety factor of the slope against friction angle for different heights and the seismic coefficient of 0

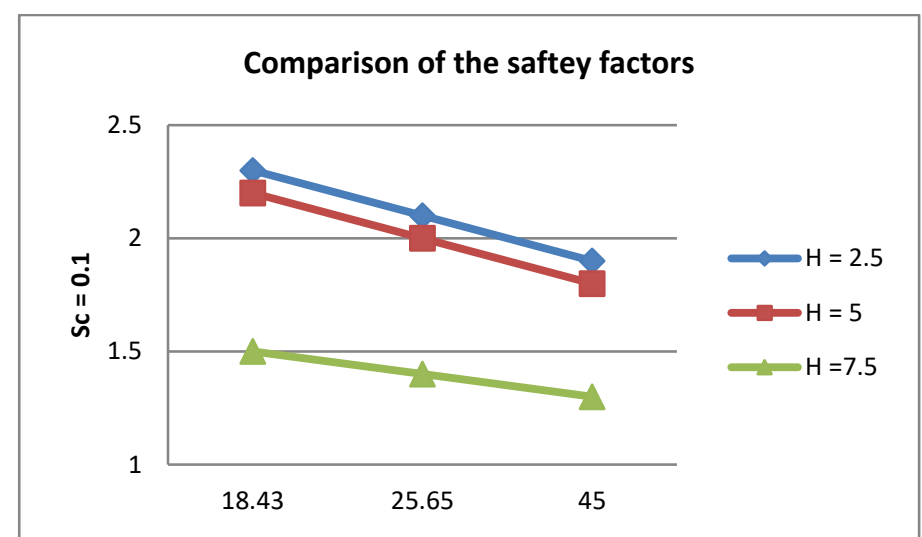

Fig. 19: Graphs of safety factor of the slope against friction angle for different heights and the seismic coefficient of 0.1

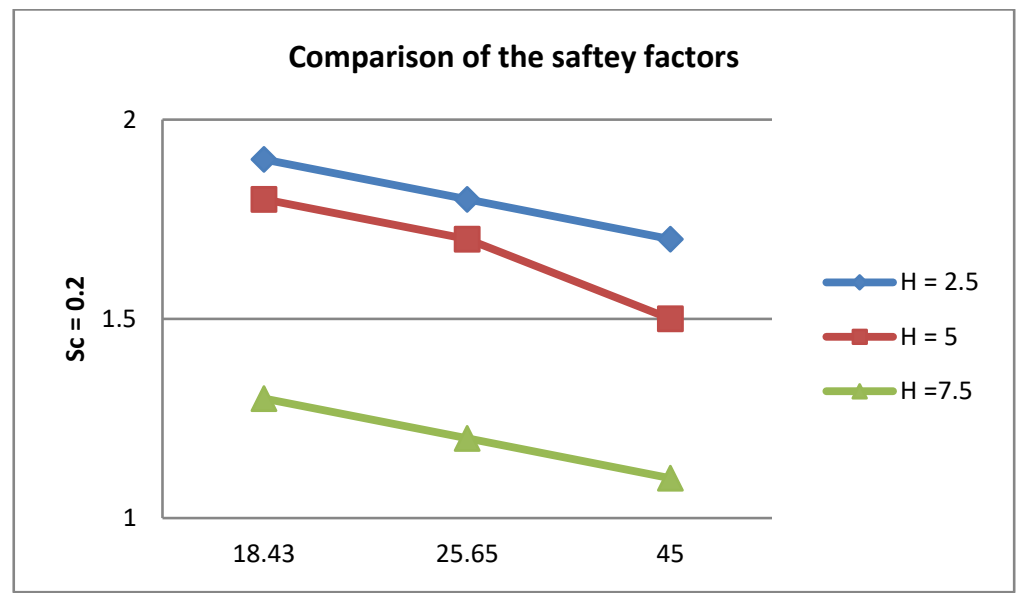

Fig. 20: Graphs of safety factor of the slope against friction angle for different heights and the seismic coefficient of 0.2

In Table 6, the comparison between the results obtained using the limit equilibrium and finite difference methods for a slope with the height of $5 \mathrm{~m}$, soil specifications of $\mathrm{C}=3 \mathrm{t} / \mathrm{m} 3$ and $\varphi=10^{\circ}$, and the seismic coefficient of 0.2 is presented.

Table 6: Comparison of the results obtained using the limit equilibrium and finite difference methods

\begin{tabular}{ccccccccc}
\hline$\beta$ & FLAC & MORGENSTERN PRICE & SPENCER & Bishop and Morgenstern & JUNBU & ORDINARY & CORP1 & CORP2 \\
\hline 18.43 & 1.8 & 1.8 & 1.8 & 1.7 & 1.6 & 1.7 & 1.7 & 1.8 \\
25.65 & 1.7 & 1.7 & 1.6 & 1.6 & 1.4 & 1.5 & 1.6 & 1.7 \\
45 & 1.5 & 1.5 & 1.4 & 1.4 & 1.3 & 1.3 & 1.4 & 1.6 \\
\hline
\end{tabular}

From the tables and graphs provided, it can be clearly concluded that the resulting values obtained using finite difference methods are slightly greater than the ones obtained using limit equilibrium methods. In addition, the results obtained from the limit equilibrium analysis are close to the finite difference analysis results and can be used for the calculation of the stability of slopes. It should be noted that the finite difference methods are more accurate than the limit equilibrium methods and that based on the results obtained using different methods, Morgenstern-Price and Spencer methods have the most accuracy (Fig. 21). 


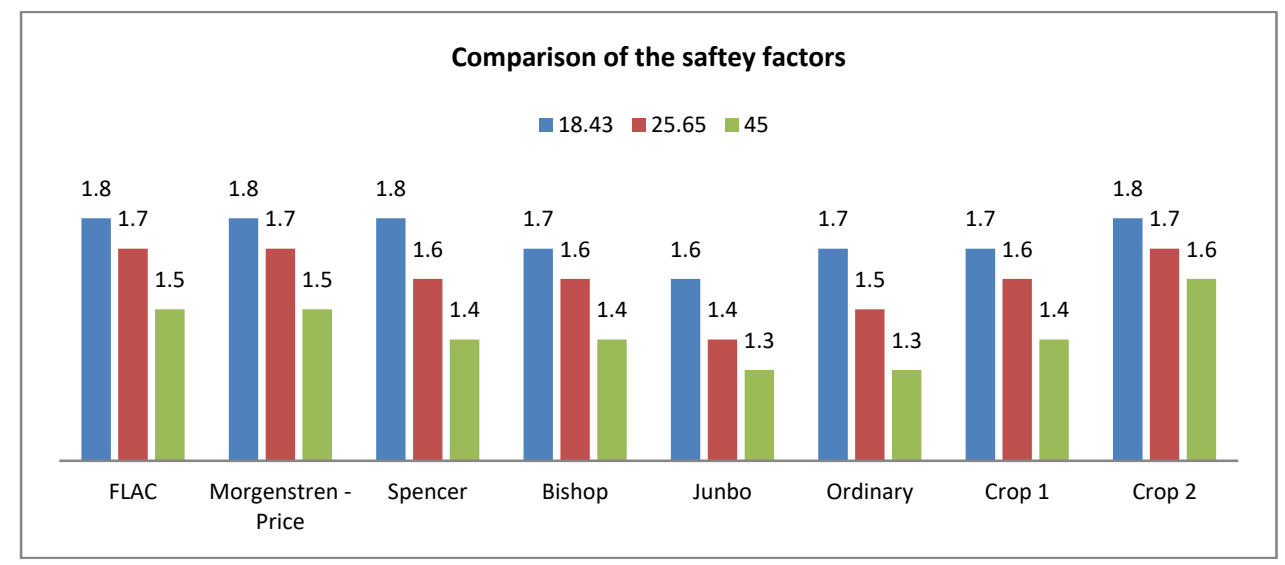

Fig. 21: Comparison of the safety factors obtained using different limit equilibrium and finite difference methods

According to the study conducted by Mendoza et al. (2009), which included a pseudo-static analysis of low-height earth dams using the Ordinary Method of Slices, there is a need for an updated and more accurate analysis as more practical and accurate methods currently exist. Meanwhile, the existence of different limit equilibrium methods causes the researchers to be uncertain which chosen method is the most accurate. In the research conducted by Mendoza et al. (2009), due to the limited extent of the study, no comparison between the different methods with the aim of determining the most accurate of them was presented and the analysis results also did not have adequate accuracy. In this research, an attempt was made that, through the comparison of the different methods available, the most accurate method of calculation is presented. In fact, with the help of the results obtained in this study, the safety factors of the slopes for a homogenous low-height dam can be determined while having the following parameters:

1. The minimum safety factor value necessary for ensuring the stability is determined. For static conditions, a safety factor (FS) value of 1.4 is normally considered.

2. Mechanical specifications of the soil ( $C^{\prime}$ and $\varphi$ ) are obtained through triaxial shear test or other valid tests. Then, while having the height of the dam and using the nomograms presented, the downstream slope is determined.

3. If multiple types of soil are used in the construction of the slope, which is normally true in most of the projects, this method can be used to determine the greatest slope necessary for each of the soil types.

4. Now, using the nomograms for a second time and while having the slope and seismic coefficient values, the safety factor of the slope is checked under pseudo-static conditions to ensure that it is in the allowed range.

5. If the safety factor is in the allowed pseudo-static range, the slope values obtained are accepted as the final values. Otherwise, the slopes are reduced and the safety factor is once again calculated so that the value obtained is in the allowed range.

\section{Conclusion}

In this study, with the presentation of a set of graphs, the fast calculation of the safety factor of the slope in dams up to $10 \mathrm{~m}$ high under static and pseudo-static conditions was made possible. In addition, a numerical comparison between the different methods for the analysis of the stability potential of the slopes during earthquakes was conducted. The most important conclusions include the following:

Limit equilibrium analyses in static conditions were compared to the study results of other researchers and the accuracy of the analyses was confirmed to a good approximation. It was also revealed that Morgenstern-Price and Spencer methods had the most accuracy among the different methods available. It should be also noted that the results obtained from finite difference and finite element analyses are very close to the results obtained from limit equilibrium analyses and could be employed for the calculation of the slope stability.

The graphs provided are intended for facilitation of the calculation of the safety factor of the slope for small earth dams less than $2.5 \mathrm{~m}$, between 2.5 to $5 \mathrm{~m}$, and between 5 to $7.5 \mathrm{~m}$ high respectively. The heights mentioned are usually used in dams intended for the storage of toxic liquids such as agricultural and urban leachates. For each height of the embankment, three different slope angles of $45^{\circ}(1 \mathrm{~V}: 1 \mathrm{H}), 26.65^{\circ}$ $(1 \mathrm{~V}: 1 \mathrm{H})$, and $18.43^{\circ}(1 \mathrm{~V}: 1 \mathrm{H})$ are considered. These graphs allow the user to calculate the safety factor for a slope with specific height and angle and known soil specifications under static and pseudo-static conditions. Using the graphs provided, the optimum slope angle for a dam could be calculated. Thus for given dam capacity and height, and based on the seismic coefficient of the area, the graph provided gives the best angle value that is geotechnically stable.

Through the analysis of the graphs, it can be observed that the increase in the height leads to the decrease of the safety factor. Meanwhile, the increase of the friction angle leads to the increase of the safety factor. It should be noted that the slope is considered stable and safe if the safety factor value under static conditions is greater than 1.4. 


\section{References}

Bishop AW and Morgenstern NR (1960). Stability coefficients for earth slopes. Geotechnique, 10(4): 129-153.

FLAC (2002). FLAC user manual. Itasca Consulting Group Inc., Minneapolis, Minesota, USA

Iman M, Abbas KA, and Erfanian Azmoudeh MH (2012). Dynamic analysis of concrete dam due to seismic forces. World Applied Sciences Journal, 17(8): 1046-1053.

Janbu N (1967). Discussion of paper “Dimensionless parameters for homogeneous earth slopes" by Bell. Journal of the Soil Mechanics and Foundations Division, ASCE, 93: 367-374.

Karbor-e-shyadeh AH and Soroush A (2008). A comparison between seismic behaviors of earth dams with inclined and vertical clay cores- a numerical analysis approach. In the $14^{\text {th }}$ World Conference on Earthquake Engineering, Beijing, China: 1-8. Available online at: ftp://jetty.ecn.purdue.edu/spujol/ Andres/files/04-02-0087.pdf

Mendoza FC, Gisbert AF, Izquierdo AG, and Bovea MD (2009). Safety factor nomograms for homogeneous earth dams less than ten meters high. Engineering Geology, 105(3): 231-238.

Morgenstern N (1963). Stability charts for earth slopes during rapid drawdown. Geotechnique, 13(2): 121-131.

Ozkan MY (1998). A review of considerations on seismic safety ofembankments and earth and rock-fill dams. Elsevier Science, Soil Dynamics and Earthquake Engineering, 17 (7): 439-458.

Parish Y, Sadek M, and Shahrour I (2009). Numerical analysis of the seismic behaviour of earth dam. Natural Hazards and Earth System Sciences, 9(2): 451-458.
Rathje EM and Bray JD (2001). One-and two-dimensional seismic analysis of solid-waste landfills. Canadian Geotechnical Journal, 38(4): 850-862.

Samir PK and Sanghavi CS (2012). Seismic slope stability analysis of kaswati earth dam. International Journal of Advanced Engineering Research and Studies, 1(3): 305-308.

SLOPE/W (2007). Geoslope 2007 User Manual. Geo-Slope International Ltd., Calgary, Alberta, Canada.

Spencer E (1967). A method of analysis of the stability of embankments assuming parallel inter-slice forces. Geotechnique, 17(1): 11-26.

Subramani T, Ponnuvel D, and Deans D (2012). Seismic and stability analysis of gravity dams using STAAD Pro. International Journal of Engineering Research and Development, 1(5): 44-54.

Tripathy LK (2011). Seismic analysis of earth dams. In the Indian Geotechnical Conference, Kochi, India: 285-288. Available online at: https://gndec.ac.in/ igs/ldh/conf/2011/articles/ T06_9.pdf

USBR (2001). Engineering geology field manual. US Bureau of Reclamation, Technical Service Center, Washington, D.C., USA.

Wieland M (2008). Earthquake safety of small dams. Chinese, Journal of Geotechnical Engineering, 30(11): 1679-1682.

Yegian MK, Marciano EA, and Ghahraman VG (1991) Seismic risk analysis for earth dams. Journal of Geotechnical Engineering, 117(1): 18-34. 